\title{
A lavagem do Rio
}

\author{
Washing up Rio
}

\author{
Jeanne Marie Gagnebin \\ Professora de filosofia da Pontifícia Universidade Católica de São Paulo \\ e da Universidade Estadual de Campinas \\ Cidade Universitária Zeferino Vaz \\ Caixa Postal, 6110 Barão Geraldo \\ 13081-970 Campinas — SP Brasil
}

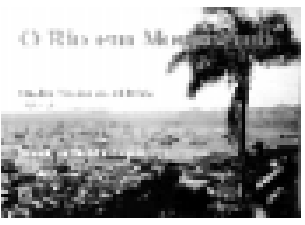

Myriam Bahia Lopes O Rio em movimento quadros médicos e $(m)$ bistória: $1890-1920$ Rio de Janeiro, Editora Fiocruz, 2001, 136p

D ara um leitor, como a autora desta resenha, que não é nenhum especialista em história, o livro de Myriam Bahia Lopes, O Rio em movimento-quadros médicos e $(m)$ história: 1890-1920, reserva surpresas instigantes. Embora trate de um período relativamente curto, de um episódio singular, a Revolta da Vacina, e restrito ao Rio de Janeiro, a obra levanta questões que dizem respeito tanto à representação do passado quanto à representação da especificidade brasileira sobre esse passado. O questionamento historiográfico salutar leva o leitor, atento à voz crítica que ali se articula certamente com discrição, mas com firmeza, a se perguntar se alguns lugares-comuns sobre a interpretação do Brasil de hoje não poderiam igualmente ser chacoalhados com proveito.

Desde o início, Myriam Bahia define seu livro como um ensaio, isto é, uma tentativa ou, como ela também diz, uma luta. O livro apresenta um momento histórico preciso, um acontecimento singular, mas, ao mesmo tempo e de forma inseparável, também procede a uma constante autoreflexão sobre as categorias empregadas nessa apresentação, categorias como "modernidade" (versus "atraso"), civilização, "regeneração" (versus "decadência"). Essa "luta implícita contra a rigidez das palavras", segundo Myriam, faz desse texto um pequeno laboratório de indagações preciosas sobre algumas idéias prontas, mesmo que bem-intencionadas e progressistas, que circulam a respeito de nossa "triste realidade nacional", como se diz, e que impedem que se tenha uma percepção mais atenta de sua complexidade, de seus paradoxos, talvez até de suas contradições e também de suas possibilidades insuspeitas.

Para estimular essa percepção mais fina, para "intervir nas imagens cristalizadas na memória histórica", a autora lança mão de uma quantidade e de uma diversidade notáveis de documentos, dos quais a lista de fontes consultadas ao final do volume dá uma boa idéia. Arquivos, bibliotecas, fundações, casas, museus, correspondências, jornais fornecem não só textos, mas também canções e imagens que mostram uma multiplicidade de visões, de interpretações e, portanto, de narrações dos acontecimentos.

Gostaria de ressaltar aqui o olhar perspicaz de Myriam Bahia quando analisa as fotografias da época, essas imagens que não reproduzem a realidade, mas são elas também construções ideológicas e artísticas. Um exemplo: a construção de 'tipos' urbanos, isto é, de figuras isoladas do seu contexto concreto de rua ou de moradia graças ao fundo, 
fornecido por um pano branco que recobre o resto, pano que o fotógrafo Marc Ferrez carrega consigo. Myriam estabelece um contraste entre várias fotografias assépticas do Rio em obras, protótipos de uma modernização urbana ordenada, e as numerosas caricaturas que revelam a sujeira, o desconforto, a exclusão dos moradores em decorrência desse mesmo processo de "modernização". Assim, as ilustrações fazem mais do que 'ilustrar' o texto escrito; tornam-se documentos à part entière que trazem outras informações possíveis e trazem-no de uma outra forma que a fornecida pelo documento escrito.

No último capítulo, especificamente consagrado à eclosão e ao desenrolar da revolta, podemos examinar croquis cuidadosamente elaborados dos bairros cariocas no dia da revolta, todos eles dotados de um sistema de convenções desenhadas pela autora, como "bonde virado", "crianças representando batalhas", "pancadarias" ou "quartel de polícia". Textos e croquis apóiam-se e comentam-se mutuamente, num esforço visível de deixar em aberto a interpretação dos acontecimentos: no cenário da cidade, que os mapas apresentam, os revoltosos encenam uma história cujo desfecho não está prefixado e cuja conclusão não é definitiva.

A respeito do fim da revolta só se pode afirmar com segurança o seguinte: "Os presos, em torno de setecentos, aguardaram na Ilha das Cobras antes de serem enviados para o Acre." A imagem corrente da Revolta da Vacina é a de um levante popular provocado pela pobreza e cujo pretexto foi a resistência da população mais simples à obrigatoriedade da vacina contra a varíola. Ademais, em vez de esclarecer o povo sobre os benefícios da medida, vários jornais de oposição aproveitaram-se de sua ingenuidade para propagar a suspeita de que a vacina transmitia doenças, em vez de combatê-las. Assim, monta-se um quadro composto pelo atraso brasileiro (em relação ao resto do mundo moderno e higiênico), pelo obscurantismo popular encorajado pela miséria e pela manipulação proveniente de algumas pessoas da elite que não têm escrúpulos.

Myriam Bahia não nega a presença parcial de tais elementos. Sua estratégia consiste, porém, em afirmar a existência geralmente ignorada ou silenciada de outras dinâmicas em jogo que permitem relativizar as conclusões cínicas ou resignadas decorrentes da versão anterior, que eram do tipo: "Enquanto houver tamanha pobreza no Brasil, não se pode esperar nenhuma independência crítica por parte do povo, que sempre se deixará seduzir por indivíduos malvados e interesseiros."

A estratégia argumentativa do livro desenvolve-se em duas direções principais. Primeiro, mostrar que a Revolta da Vacina também se inscreve em um movimento de resistência popular muito mais amplo contra a 'modernização' do Rio de Janeiro. Segundo, mostrar que os argumentos ideológicos e científicos contra a vacina obrigatória também remetem a uma outra concepção igualmente coerente da medicina, concepção defendida por vários movimentos internacionais.

O primeiro passo da obra baseia-se numa evocação cuidadosa das transformações urbanísticas impostas pelo governo à capital do Brasil. O Rio de Janeiro devia passar de uma cidade colonial atrasada, suja, malcheirosa, símbolo de um Império decadente, para uma capital moderna e limpa, 
imagem da nova ordem republicana e das ambições políticas renovadas do Brasil no cenário internacional. Contra o atraso tropical colonial, tratava-se de "integrar o Brasil no mundo civilizado" (nas palavras de Stepan citadas por Bahia), e isso através de duas operações higiênicas diferentes, mas paralelas: operação de saneamento da cidade e operação de vacinação da população. O livro estabelece uma analogia muito fecunda entre o espaço físico da cidade, o corpo urbano, por assim dizer, e o corpo individual singular de cada cidadão. Os dois corpos devem ser limpos, sadios, higiênicos, isto é, também delimitados, controláveis e controlados.

Assim, como na Paris de Hausmann, aqui, a destruição dos bairros populares e dos cortiços não serve à erradicação da pobreza (que continua e migra para os morros ou para a periferia). Ela visa, talvez antes de tudo, à delimitação disciplinadora de uma população que sabia viver sem domicílio nem trabalho fixos e ocupar um espaço urbano sem seguir as regras estabelecidas pelas autoridades. A rua colonial, local reservado a homens vagabundos, capoeiras, ladrões, negros quadrilheiros, prostitutas, mendigos ou penitentes (sic)" — só faltam os nossos camelôs -, devia ceder lugar a largas e modernas avenidas, como a avenida Central, de recorte claro e racional, pelas quais transitam indivíduos ordeiros, isto é, com família e lar determinados, locais de trabalho e de diversão definidos. Trata-se, diz Myriam, de "fixar os indivíduos pelo lar, promovendo a família, e, ao mesmo tempo, fazê-los circular por uma rede de trajetórias previstas e de instituições normativas, tais como as ruas, as praças, a casa de comércio, a escola, a fábrica e a moradia".

A introdução da iluminação a gás nas ruas e nas casas sem dúvida aumenta a segurança dos cidadãos, mas também permite um controle mais eficaz de seus afazeres e movimentos. A escuridão ameaçadora, mas também aconchegante, no seio da qual todos os negócios lícitos e ilícitos são possíveis, é substituída pela visibilidade invasiva: não foi por acaso que os revoltados da vacina destruiriam os postos de iluminação e mergulhariam os bons burgueses proprietários no "medo de escuro" e na insônia, segundo uns versos satíricos de Xiquote, de 1905.

Ora, essa intervenção agressiva no corpo da cidade, que tinha crescido certamente de maneira "desordenada", mas seguindo a ordem dos ritmos e das necessidades de seus habitantes, essa intervenção repetia-se agora sob a forma da obrigatoriedade da vacina, pela ação das brigadas sanitaristas que, acompanhadas por policiais, entravam à força nas casas e espetavam os corpos indefesos da população. Em termos simbólicos, é uma invasão semelhante que desaloja agora o indivíduo não só da sua rua ou da sua moradia, mas também do seu próprio corpo, seu espaço mais íntimo e incontestado.

Não se tratava somente de convencer a população a vencer um medo irracional diante da lanceta. Também não podemos esquecer dos inúmeros 'acidentes' (reações mórbidas à vacina) provocados, entre outros fatores, pelas péssimas condições de transporte da vacina, que geravam desconfiança na população e que seriam silenciados pela historiografia futura, pronta a denunciar rapidamente a falta de esclarecimento científico. Tratava-se, antes de mais nada, de uma outra relação do sujeito com seu próprio corpo: este não era visto como um organismo cuja saúde dependia do saber de outros (enfermeiros, 
médicos, cientistas) e que devia, portanto, se prestar a manipulações e a controles benéficos por parte dessas autoridades. Mais fundamentalmente, o corpo pertencia ao sujeito de maneira tão íntima e imediata que este nem podia dizer que era seu, como se fosse propriedade sua: ele não era nem mesmo 'dono' do seu corpo, mas existia nele, ele o era. Sentimento primeiro e difuso que talvez não chegue a se explicitar verbalmente, mas que está na raiz da resistência à intervenção sanitarista pública, percebida como uma desapropriação íntima e um controle repressivo sob o gesto da prevenção.

Nesse segundo momento de sua exposição, Myriam detém-se e puxa de sua manga de arguta historiadora dois trunfos inesperados: a concepção holística de muitos médicos positivistas da época, no Brasil, e a presença de um forte movimento internacional, nos meios médicos e políticos, contra a vacinação obrigatória, fato negligenciado pela historiografia da revolta. A análise de vários documentos e de inúmeras declarações, em particular na imprensa, de médicos ou de notáveis, membros da Igreja e Apostolado Positivista do Brasil (IAPB), revela uma concepção singular da saúde e do saber médico. A concepção remonta a Hipócrates e continua viva em práticas atuais como a homeopatia. Ela repousa na afirmação da interligação entre o meio biológico e o meio social, inaugurando uma nova teoria, a mesologia. Daí decorre uma concepção holística da saúde e de sua preservação. O médico deve ajudar o paciente a manter o equilíbrio natural, que é definição da saúde, e a fortalecê-lo quando ele se torna precário, mas sem recorrer a intervenções diretas no funcionamento dos órgãos.

No quadro da doutrina positivista da sociedade, o dever de manutenção da saúde não faz parte das atribuições do Estado, não pertence ao domínio público. A saúde só se fortalecerá se houver um projeto moralizador da população para retornar às sagradas leis da natureza, em particular à preponderância dos laços familiares na educação, na formação e na manutenção da vida, passando pela reabilitação do papel central da mulher, elo privilegiado entre o natural e o social. Por essas razões, numerosos positivistas se opunham às "instituições de seqüestro ( (ic)", tais como a escola e o hospital, que retiravam o indivíduo do seu meio natural originário, isto é, da família.

Myriam não esconde o viés reacionário dessas teorias. Mas ela insiste no fato de que os médicos positivistas — que não são unânimes entre si; é importante ressaltar várias diferenças, em particular entre cariocas e paulistas — apresentavam uma teoria coerente que não era simplesmente uma cópia grotesca de seus mestres europeus. Sobretudo a luta entre positivistas e sanitaristas não é uma discussão entre charlatães supersticiosos e cientistas integros, mas um "debate travado entre duas figuras de saber": de um lado, uma concepção holística da saúde decorrente de uma teoria do meio; do outro, a teoria do agente específico de cada doença, isto é, a possibilidade de descoberta de estratégias e de técnicas específicas singulares (remédios, injeções, vacinas, operações etc.) que permitem lutar contra esses agentes isolados.

Pesquisando o acervo particular de um ilustre médico positivista, membro do IAPB, J. C. Bagueira Leal, Myriam encontrou cartas da Anti-Vaccination League of America e da National Anti-Vaccination League da Inglaterra. 
Bagueira Leal, aliás, seria eleito vice-presidente honorário da liga norteamericana em outubro de 1908. Myriam analisa aqui rapidamente os argumentos do movimento inglês (ela os estudará com mais detalhes em sua tese de doutoramento, concluída em Paris em 1997). À diferença da argumentação positivista brasileira, de cunho mais religioso - mesmo que se trate de uma teoria religiosa da natureza - os antivacinistas ingleses filiavam-se a uma longa tradição de luta dos radicais, segundo a qual "a ingerência estatal no domínio privado dos corpos cria o direito de resistência dos cidadãos".

A rica correspondência entre os antivacinistas brasileiros e seus colegas ingleses ou americanos revela a existência, apesar das diversas filiações, de um debate internacional importante, de relevância científica e política, sobre as novas práticas sanitaristas: a luta contra a vacinação obrigatória significa, portanto, muito mais que uma grotesca resistência de pseudocientistas da periferia tropical do mundo civilizado.

Concluamos. Ao lado da engenhosa e precisa pesquisa histórica, o maior mérito do ensaio parece ser sua capacidade de recontar um episódio da história brasileira sem cair nem no relativismo historiográfico nem no posterior acerto de contas para decidir quem estava com (a) razão. Essa revisão cuidadosa dos esquemas narrativos e interpretativos em uso na história da Revolta da Vacina permite vislumbrar uma outra hipótese. E se essa luta popular não fosse o mero levante de pobres miseráveis, atrasados e ignorantes, mas muito mais a tentativa de esboçar uma outra organização do espaço: do espaço exterior, da cidade, como palco da invenção de outras práticas de habitação; do espaço interior, dos corpos, como territórios não controláveis da invenção da vida? 